\title{
Looking at Intelligence from So-Called Noncognitive Traits: Be Open to Change
}

\section{Matthias Ziegler}

Psychological Institute, Humboldt-Universität zu Berlin, Unter den Linden 6, Berlin 10099, Germany; E-Mail: zieglema@hu-berlin.de; Tel.: +49-30-2093-9447; Fax: +49-30-2093-9361

Received: 18 November 2013; in revised form: 9 January 2014 / Accepted: 14 January 2014 /

Published: 22 January 2014

\begin{abstract}
Within this commentary, I will try to extend the views presented in Johnson's, as well as Hunt and Jaeggi's, commentaries. Both commentaries address the issue of intelligence development. I will try to broaden the discussion by including noncognitive traits as predictors of cognitive development. These ideas are founded within the environmental enrichment hypothesis and the Openness-Fluid-Crystallized-Intelligence (OFCI) model.
\end{abstract}

Keywords: intelligence; development; environmental enrichment; environmental success; OFCI model

\section{Introduction}

Johnson as well as Hunt and Jaeggi present excellent and stimulating views on contemporary intelligence research. Unfortunately, there is not enough space to dwell on all the exciting perspectives and insights they made. Therefore, I will restrict my commentary to the development of intelligence. Hunt and Jaeggi stress that an aging society clearly calls for means to improve and maintain cognitive ability. They further identify three ways that have been used so far: physical intervention, interventions to improve information processing and education. Thus, changes in intelligence are sought out through external means, with a potentially direct influence on the cognitive system. Johnson also addresses these issues but, furthermore, discusses the natural development of intelligence addressing the issue of gene environment interaction, as well as the role of performance feedback. Her view is that those who experience fast success in learning environments will enjoy this positive feedback, developing interest, 
motivation, and other positive personality traits conductive to cognitive development. This view is often called the environmental success hypothesis [1,2].

However, both approaches might underestimate the important role noncognitive traits can have on the development of cognitive ability. In that sense, research needs to acknowledge intelligence as an outcome variable.

\section{The Impact of Noncognitive Traits on the Development of Intelligence}

In a recent study it was suggested that openness to experience might act as a buffer against cognitive decline [3]. A possible mechanism for this was suggested by Ziegler et al. in their OpennessFluid-Crystallized-Intelligence (OFCI) model [2]. Here, it is argued that being open and curious will bring a person into more learning situations which, in turn, will influence the development of fluid intelligence. The mechanism is called environmental enrichment hypothesis according to Raine et al. [4]. Moreover, the model includes a causal influence of fluid intelligence on the development of openness based on the environmental success hypothesis. The investment hypothesis by Cattell is also part of the model. Finally, the model includes an indirect effect of openness on the development of crystallized intelligence via its influence on fluid intelligence. Longitudinal support for this idea was provided within a sample of young adults, and for a time span of 6 years [2]. Ziegler et al. also speculated about the influence of interests and situational conditions on these mechanisms. It has to be noted that a study with old people did not find similar effects [5]. However, as Ziegler et al. pointed out, the positive effects of openness on the development of cognitive ability are most likely if the current life situation allows for them to manifest. Specifically, early adulthood or the beginning of retirement might be times when being open especially pays off. Moreover, the study by von Stumm and Deary applied a cross-lagged analysis which has been shown to yield findings that are not necessarily evidence for causal relations [6]. Thus, despite these findings, the question of what came first, cognitive ability or personality traits, needs further research (see also [7]). There are many other traits that could have similar influences, e.g., need for cognition or typical intellectual engagement. However, as a paper by Mussel [8] shows, openness can be seen as the overarching framework. The same holds true for possible gene environment interactions as mentioned by Johnson in her commentary. However, considering the multitude of longitudinal studies being conducted now, as well as the improved accessibility of such data, this certainly opens up further opportunities to test the role of noncognitive traits for the development of cognitive ability.

Summing up, this commentary applauds the commentaries by Johnson, and Hunt and Jaeggi but also tries to convey the idea that it is time to shift research attention towards factors influencing intellectual development which lie within persons or person-by-situation interactions.

\section{Conflicts of Interest}

The author declares no conflict of interest.

\section{References}

1. Cattell, R.B. Intelligence: Its Structure, Growth and Action; North-Holland: Oxford, UK, 1987. 
2. Ziegler, M.; Danay, E.; Heene, M.; Asendorpf, J.; Bühner, M. Openness, fluid intelligence, and crystallized intelligence: Toward an integrative model. J. Res. Personal. 2012, 46, 173-183. doi:10.1016/j.jrp.2012.01.002.

3. Williams, P.G.; Suchy, Y.; Kraybill, M.L. Preliminary evidence for low openness to experience as a pre-clinical marker of incipient cognitive decline in older adults. J. Res. Personal. 2013, 47, 945-951. doi:10.1016/j.jrp.2013.09.006.

4. Raine, A.; Reynolds, C.; Venables, P.H.; Mednick, S.A. Stimulation seeking and intelligence: A prospective longitudinal study. J. Personal. Soc. Psychol. 2002, 82, 663-674.

5. Von Stumm, S.; Deary, I.J. Intellect and cognitive performance in the Lothian Birth Cohort 1936. Psychol. Aging 2013, 28, 680-684. doi:10.1037/a0033924.

6. Rogosa, D. A critique of cross-lagged correlation. Psychol. Bull. 1980, 10, 245-258.

7. Von Stumm, S. Investment trait, activity engagement, and age: Independent effects on cognitive ability. J. Aging Res. 2012, 2012, 949837:1-949837:7. doi:10.1155/2012/949837.

8. Mussel, P. Intellect: A theoretical framework for personality traits related to intellectual achievements. J. Personal. Soc. Psychol. 2013, 104, 885-906. doi:10.1037/a0031918.

(C) 2014 by the authors; licensee MDPI, Basel, Switzerland. This article is an open access article distributed under the terms and conditions of the Creative Commons Attribution license (http://creativecommons.org/licenses/by/3.0/). 